Revista Eletrônica de Ciência Administrativa (RECADM) - ISSN 1677-7387

Faculdade Cenecista de Campo Largo - Coordenação do Curso de Administração

v. 2, n. 2, nov./2003 - http://revistas.facecla.com.br/index.php/recadm/

\title{
O CONCEITO OPERACIONAL DE INOVAÇÃO TECNOLÓGICA
}

\author{
PINHEIRO, Daniel Rodriguez de Carvalho ${ }^{1}$
}

\section{RESUMO}

Um dos problemas para pesquisadores que investigam as mudanças tecnológicas do ponto de vista das ciências sociais aplicadas é saber precisamente o que é tecnologia. $\mathrm{E}$ quando ocorre uma mudança tecnológica. O objetivo deste texto é colaborar para esse debate tentando construir um conceito operacional de tecnologia a partir dos documentos produzidos no final dos anos de 1990 e início dos anos 2000, e reunidos pela Financiadora de Estudos e Projetos - FINEP em CD-ROM. Para elaborar a primeira versão do conceito operacional de tecnologia fez-se uma análise dos diversos conceitos reunidos pela FINEP seguindo uma ordem: do primeiro para o último. A crítica ao material propunha que um conceito é a tentativa de dizer o que alguma coisa é ou como funciona. E conceito operacional é aquele que foi constituído a partir de indicadores empíricoanalíticos. Feito isso, o conceito provisório foi sendo enriquecido pelo debate com cada um dos novos conceitos que eram examinados. A busca de um conceito operacional de tecnologia mostrou que há pesquisadores que entendem tecnologia como coisas (máquinas, equipamentos, instalações) e há pesquisadores que investigam tecnologia considerando as coisas e os processos de trabalho. O que fiz foi reunir as duas tendências num único conceito.

Palavras-chave: Tecnologia; capital; mudança tecnológica; processo de trabalho; conceito.

\begin{abstract}
One of de problem faced by researchers who investigate the technological change from the viewpoint of applied social sciences is to know precisely what technology is and when a technological change takes place. The concept of technology based on the pappers elaborated among the year of 1990 and 2002 and which were gathered by the Finep - Finaciadora de Estudos e Projetos (Projects and studies sponsor) in one cd-rom. In order to elaborete the first ver of the operational concept of technology it was made an analysis of the different concepts reunited by the Finep following an order: from the first to the least one. The critics of the material proposed that the concept of something is the attempt tosay what this something is or how it is works. The operational concept is made up from empiric-analytical landmarks. Having done this, the provisory concept enriched gradually by the discussion provided the examination of the concept studied later. The search for an operational concept of thing,(machinery, equipment, facilities) and the researchers that understand technology considering the things and the work processes. I reunited both tendencies in a unique concept. .
\end{abstract}

Keywords: Technology; capital; technological change; work process; concept.

${ }^{1}$ Graduado em Arquitetura e Urbanismo e Doutor em Sociologia. E-mail: daniel@uece.br. 
Revista Eletrônica de Ciência Administrativa (RECADM) - ISSN 1677-7387

Faculdade Cenecista de Campo Largo - Coordenação do Curso de Administração

v. 2, n. 2, nov./2003 - http://revistas.facecla.com.br/index.php/recadm/

\section{INTRODUÇÃO}

Para evitar uma longa discussão epistemológica, diz-se que conceito é uma tentativa de dizer o que alguma coisa é ou como alguma coisa funciona. Poder-se-ia tentar dizer o que é homem ou como funciona um turbo intercooler. Em ambos o caso, teria um coneito.

Conceito operacional é aquele que, por causa de suas características, poderia ser usado na pesquisa empírico-analítica, porque permite que se faça a diferenciação entre coisas muito parecidas. Por exemplo. Pode-se dizer que o homem é um racional, mas é difícil identificar um homem às 3 horas da madrugada num baile de carnaval tendo como principal predicado desse homem a racionalidade. Mas se o homem for conceituado através de um predicado que possa ser percebido como fato, como da capacidade de expressar de forma verbal ou não-verbal suas necessidades materiais, psíquicas, espirituais ou racionais e alguém grita: "Garçom, uma cerveja!", eis aí provavelmente um homem, porque esse ser expressou uma necessidade.

Com estes aforismos, pode-se expressar o problema dessa discussão nos seguintes termos: que eventos indicam inovação tecnológica? Tais eventos ou predicados, quando e informações, são os indicadores empíricos.

\section{INDICADORES EMPÍRICOS DE INOVAÇÃO TECNOLÓGICA}

A ANPEI - Associação Nacional de Pesquisa, Desenvolvimento e Engenharia das Empresas Inovadoras (por extenso) usou dezoito indicadores empíricos de esforço de desenvolvimento tecnológico: quatro da categoria despesas; dois indicadores de ativos fixos; seis indicadores de pessoal ocupado nos processos; um indicador das instalações; um de projetos, patentes, receitas, faturamento e um de redução de custos ${ }^{2}$.

a) Despesas com P\&D - Gastos de custeio (salários, encargos, materiais de consumo, depreciação etc.) feitos diretamente na geração de conhecimento tecnológico novo em virtude de pesquisa básica, pesquisa aplicada e desenvolvimento experimental, daqui por diante chamada de pesquisa e desenvolvimento (P\&D).

b) Despesas com serviços tecnológicos - Gastos com atividades de suporte de P\&D e com manutenção dos equipamentos utilizados nas pesquisas. Por exemplo, treinamento de pesquisadores, documentação técnica etc.

c) Despesas com aquisição de tecnologia - Gastos com royalties, assistência técnica e serviços técnicos especializados. O royalty é o valor pago ao detentor de uma marca, patente, processo de produção, produto ou obra original pelos direitos de sua exploração comercial. Os detentores recebem uma porcentagem das vendas dos produtos produzidos com o concurso de sua marca, patente, processo etc., ou dos lucros obtidos com essas operações comerciais.

d) Despesas com engenharia não rotineira - Gastos com atividades da engenharia diretamente relacionada ao processo de inovação tecnológica.

e) Despesas com P\&D\&E - Nesse caso, trata-se não de um indicador propriamente dito, mas de um conjunto de indicadores somados. As despesas de P\&D\&E somadas as despesas com P\&D, serviços tecnológicos, aquisição de tecnologia mais as despesas com engenharia não rotineira. Portanto, isto é a síntese das despesas com inovação tecnológica.

f) Investimentos de inovação tecnológica - Os investimentos classificados como inovação tecnológica se referem a aquisição de ativos.

\footnotetext{
${ }^{2} \mathrm{O}$ quadro de indicadores de inovação tecnológica da ANPEI, originalmente produzido por economistas e engenheiros, teve sua linguagem traduzida para o modo de falar da sociologia, com a inclusão de conceitos auxiliares da teoria econômica e a engenharia de produção.
} 
Revista Eletrônica de Ciência Administrativa (RECADM) - ISSN 1677-7387

Faculdade Cenecista de Campo Largo - Coordenação do Curso de Administração v. 2, n. 2, nov./2003 - http://revistas.facecla.com.br/index.php/recadm/

g) Investimentos em ativos fixos - Ativos são os bens, valores, dinheiro, estoque de mercadorias, terrenos, instalações, máquinas, luvas, créditos e semelhantes que constituem o patrimônio da firma, por oposição a passivo, que são as dívidas e outras obrigações. Ativo fixo ou capital fixo é tudo aquilo que a empresa precisa para o processo de trabalho e que não pode ser diretamente convertido em dinheiro, incluindo-se aí imóveis, equipamentos, instalações, máquinas, ferramentas, patentes etc. O investimento em ativo fixo, que é o montante anual de investimentos feitos em capital fixo para capacitação tecnológica, é um indicador do esforço de inovação.

h) Investimentos em ativos intangíveis - Montante anual efetivamente aplicado na compra de direitos sobre licenças, patentes e tecnologia industrial.

i) Pessoal ocupado com inovação tecnológica. Pode ser:

. TNS - Técnicos de nível superior: doutores, mestres e graduados que exercem atividade predominantemente técnica.

TNM - Técnicos de nível médio: pessoal sem nível superior que exerce atividade predominantemente técnica.

ADM/OUT - Administrativos e outros: Funcionários de nível superior ou médio que exercem atividade de natureza administrativa ou gerencial.

j) Pessoal de P\&D - Soma dos funcionários TNS, TNM, pessoal administrativo e outros integralmente ocupados nas pesquisas e desenvolvimento de novas tecnologias.

k) Pessoal de engenharia não rotineira - Número total de profissionais de nível superior (doutores, mestres e graduados), médio, de administração e gerência integralmente alocados nas atividades da engenharia não rotineira.

I) Pessoal de P\&D\&E - Soma do pessoal de P\&D com o pessoal da engenharia não rotineira.

m)Instalações utilizadas para a inovação tecnológica. Podem ser: Área física ocupada por laboratórios em $\mathrm{m}^{2}$;

Área total construída ocupada efetivamente por laboratórios de pesquisa e desenvolvimento, P\&D.

n) Projetos de inovação tecnológica finalizados. Podem ser:

. Projetos finalizados;

Percentual dos projetos de capacitação tecnológica que não foram interrompidos no decorrer dos últimos três anos (1993-1996).

o) Patentes obtidas no país e/ou no exterior - A patente é um documento emitido pelo bureau de registro de patentes dos governos nacionais, reconhecendo a determinada pessoa física ou jurídica o monopólio de uma invenção por um tempo determinado. No Brasil, as patentes têm validade de 15 anos. Nos Estados Unidos, 17 anos. A pesquisa, entretanto, considera o número de patentes concedidas à empresa ou depositadas no Brasil ou no exterior, nos últimos dez anos.

p) Receita da inovação tecnológica advindas da venda de tecnologia para terceiros Receitas obtidas com a venda de tecnologia e expressas em dólares americanos.

q) Faturamento gerado por produtos novos - A fatura ou nota fiscal é o documento que comprova a venda de mercadoria e impostos cobrados sobre a operação. A fatura não comprova o pagamento; aliás, no Brasil, as notas fiscais trazem inscrito que elas não têm valor de recibo. O recibo comprova o pagamento relativo à fatura nele escriturada. O faturamento é o rendimento obtido pela venda de mercadorias, bens ou serviços de uma firma. A receita é a soma de todos os rendimentos, incluídos aí o faturamento, juros, aluguéis, correção monetária etc. Neste caso, o indicador empírico é o percentual do faturamento obtido pela venda de produtos lançados no mercado há menos de 5 anos.

r) Redução dos custos decorrentes da melhoria de processos - Relação percentual entre o montante de economia de custo decorrente de melhorias de processo introduzidas nos últimos 45 anos e o valor do lucro bruto. 
Revista Eletrônica de Ciência Administrativa (RECADM) - ISSN 1677-7387

Faculdade Cenecista de Campo Largo - Coordenação do Curso de Administração

v. 2, n. 2, nov./2003 - http://revistas.facecla.com.br/index.php/recadm/

Há quem diga que as novas tecnologias anunciam uma reviravolta na história contemporânea. Há quem discorde; Haxley (1982), por exemplo. Poder-se-ia começar essa discussão fazendo, como em muitos textos, um longo e pedante exame das condições externas dessa querela. No caso presente, como dizia Weber (1985), parto da seguinte indagação: que é mesmo tecnologia?

Identificar um conceito de tecnologia na sociologia é uma tarefa mais difícil do que se possa supor. Em geral, essa tem sido uma discussão principalmente estética. Aqui e ali, no meio do brilho das máquinas, alguém suspende a admiração selvagem pela novidade e tenta refletir conceitualmente. Comecemos por quem prefere elucidar os conceitos; Bejamin Coriat é um deles.

Para Coriat (19880), é uma nova engenharia de produção que combina inovações tecnológicas e inovações organizacionais e que, efetivamente, está levando à superação do paradigma da administração taylorista e fordista. Cito:

Para responder a esta questão é necessária uma caracterização econômica formal
do paradigma taylorista. Admito, a partir de Shon-Rethel (1977), que o paradigma
taylorista 'funda-se basicamente sobre um sistema de tempos alocados e impostos
numa economia em que a intensidade do trabalho constitui a variável estratégica
para fixar os custos de". produção'. Pode-se admitir, então, que com as novas
tecnologias, há uma modificação desse paradigma central. De fato, ao se reforçar
o processo de inovações tecnológicas, a fixação dos custos de produção passa a
se basear cada vez menos na pura intensificação do trabalho vivo, e cada vez
mais na taxa de utilização das máquinas e instalações. Dito de outra forma, a
ênfase recai sobre outra otimização: a gestão do capital fixo e do capital circulante.
Passa-se, assim, de um paradigma baseado na 'organização do trabalho' para um
paradigma baseado na 'organização da produção'. Essa transição aponta para um
esforço no sentido de enfatizar uma gestão". mais otimizada do capital fixo e do
capital circulanate, com uma conseqüente inflexão das pressões relativas à
intensificação do trabalho (Coriat, 1988, p. 59, grifos meus).

Veja que Coriat (1988) discute as novas tecnologias industriais a partir de sua pesquisa sobre os processadores microeletrônicos. Mas surpreende-se ao perceber que as tais tecnologias não têm a importância que supunha inicialmente. Mas note-se que Coriat, Tauile, Schimitz, Falabella e Piragibe (1988) não tentaram esboçar um conceito de tecnologia aplicável à nova situação em que capital e trabalho, máquinas e homens são combinados. E essa deficiência também chega a outros pesquisadores

Tratando das mudanças no modo de trabalhar e de viver que resultam do emprego das novas tecnologias, Caspar ${ }^{3}$ apresenta o que deve ser seu conceito de novas tecnologias:

Elas [as novas tecnologias] se inscrevem num duplo movimento que caracteriza as sociedades desenvolvidas de hoje: a inserção cada vez maior de inteligência nos objetos, nas máquinas, nos processos de informação e comunicação, de comercialização e, ao mesmo tempo, a mobilização crescente da inteligência nos processos econômicos e sociais (1995, p. 81).

De certo, esse é um conceito que tem muitos méritos. Nem discuto. Mas é inútil para esta pesquisa empírica. Não é operacionalizável. Depois, como diz Penrose (1991), a palavra inteligência, que é chave no conceito de tecnologia de Casper, não se aplica ainda aos objetos. Não há objetos ou máquinas inteligentes. Inteligência artificial ainda é

3 "Ciência e tecnologia hoje" (Witkows, 1995) é uma coletânea de 200 artigos, a maioria resumo de artigos e livros dos próprios autores escritos um pouco antes da coletânea. Na verdade, trata-se de um balanço do impacto sobre a vida e o trabalho e da dispersão do desenvolvimento científico e tecnológico dividido em três seções. 
Revista Eletrônica de Ciência Administrativa (RECADM) - ISSN 1677-7387

Faculdade Cenecista de Campo Largo - Coordenação do Curso de Administração v. 2, n. 2, nov./2003 - http://revistas.facecla.com.br/index.php/recadm/

uma metáfora. E se existe, essa máquina deve ser capaz de passar pelo Teste de Turing, o que nenhuma máquina, até hoje, conseguiu fazer. Ou como Penrose afirma:

Os computadores já são capazes numerosas tarefas que, antes, eram províncias exclusivas do pensamento humano, com velocidade e precisão que ultrapassam, e muito, qualquer coisa que o ser humano possa realizar. (...) Mas ser capaz de pensar - isso tem sido prerrogativa humana (1991, p.1, grifos meus).

Da mesma perspectiva doutrinária, Fichier (1995) fala do uso cada vez mais intensivo dos cartões com chip, uma invenção de 1972, que, nos anos de 1980, tornaramse populares, por exemplo, nos telefones públicos brasileiros e franceses. Uma comodidade que permite cobrar coisas antes impensáveis, como uma transmissão de televisão, muito antes de aparecerem os canais por assinatura. Contudo, ele não tenta dizer nessa obra o que é tecnologia.

David (1995) fala que o transporte coletivo com condução integralmente automática resolverá a questão da condução urbana de pessoas e cargas. Akrich (1995), socióloga do Centro de Sociologia da Inovação, École de Mines, Paris, culpa os manuais de instrução pelo bug das máquinas. Para Busson (1995), a televisão com imagem digitalizada resolverá a pendenga entre a indústria eletrônica japonesa e européia sobre as normas de transmissão de imagem. Moatti (1995) não percebe as tecnologias médicas como um negócio. Para Veltz (1995), o trabalho direto de produzir coisas está sendo sucedido pela tarefa de supervisionar, manter e organizar. $O$ treinamento em serviço com os recursos da multimídia, grupwares e programas de documentação e de gestão de textos da Renault e Sociedade Nacional das Ferrovias Francesas entusiasmam Levy. Pélata, recorrendo ao conceito de pensamento complexo de Edgar Morin, coloca o desafio de se produzir um novo carro no mundo contemporâneo. Mas nenhum deles tem, nesses textos, um conceito de tecnologia.

Moles (1995), um especialista em psicologia social, discute qualidade de vida da perspectiva do indivíduo e percebe bem que, nas relações com as indústrias e as coisas, há uma dimensão econômica e outra política, com implicações sobre o conforto na vida privada. Carré (1995), ao relacionar todos os novos meios e ferramentas de comunicação interna e externa à empresa, conclui que as novas mídias obrigam as empresas a rever as organizações. E entre as conseqüências das novas possibilidades de telecomunicação estão os empregos precários, a terceirização, os novos ofícios (arquiteto de redes, webdesigner, videografistas). E os empregos mais tradicionais e burocráticos evoluem para empregos técnico-comerciais ou até de marketing.

O crescimento dos serviços é uma das conseqüências da nova industria. Strobel (1995) trata precisamente do crescimento dos três subsetores de serviços: a) o técnicoadministrativo e sociocultural majoritariamente feminino, um tanto estável e relativamente bem remunerado; b) os serviços comerciais e pessoais reúnem as pessoas mal qualificadas, mal remuneradas, flexíveis (informal); e c) os serviços para-industriais (transportes, comércio atacadista), que conservam empregos de operários. Strobel, todavia, não é dos mais otimistas em relação ao futuro próximo. Para ele, a fragmentação no modo de gerenciar a força de trabalho não deixa de ter conseqüências negativas sobre os rendimentos do trabalhador (1995, p. 41-42).

Petit (1995) desfila suas razões para o emprego de novas tecnologias que nas décadas de 1950 e 1960 geraram níveis baixos e estáveis de desemprego. Nos anos 70, as empresas em crise têm queda na oferta de emprego. $E$ nos anos 80 , apesar do crescimento da economia, aumenta o desemprego, especialmente, na indústria. Este paradoxo contemporâneo é explicado por Petit de duas maneiras. Primeiro, o progresso técnico é retardado pelo aprendizado e ajustamento das estruturas produtivas. Segundo, as medidas de produtividade estão superadas ou há outros bloqueios ligados à 
Revista Eletrônica de Ciência Administrativa (RECADM) - ISSN 1677-7387

Faculdade Cenecista de Campo Largo - Coordenação do Curso de Administração

v. 2, n. 2, nov./2003 - http://revistas.facecla.com.br/index.php/recadm/

desorganização e à instabilidade do mercado global que são responsáveis pela estagnação da economia mundial (1995, p. 44).

Berry (1995) não vê, no futuro, uma indústria sem homens. Não está entre os ficcionistas empolgados pelas possibilidades da robótica e da informática. Estaria mais propenso a admitir que o problema da revolução tecnológica não é a máquina, é mudar as organizações, os princípios da administração, as referências culturais e as relações sociais.

Joly (1995), ao discutir o papel das biotecnologias na produção agrícola, não faz um balanço das pesquisas ou das possibilidades futuras. O que o preocupa é o fato de que as biotecnologias levam ao aumento da concorrência entre os grandes conglomerados de produção agrícola. Depois, as biotecnologias estão sob o controle das grandes empresas químicas. "Ora, cabe perguntar-nos se decisões essenciais de investimento orientadas por cálculo privado não vão ocultar certas opções fundamentais" (1995, p.53).

A tecnologia industrial desempenha um duplo papel: renovar os produtos e baixar os custos de produção. Conseqüentemente, a pesquisa e desenvolvimento científico permitem capacitar a indústria para conceber novos produtos e novas técnicas de fabricação.

Benghozi, mais conhecido pelo livro "Innovation et gestion de projets" (1990), discute a lógica da inovação e da gestão de projetos de novos objetos, convencido de que as empresas precisam diversificar a linha de produção, incluindo-se as parcerias necessárias ao desenvolvimento desses desenhos de objetos industriais ${ }^{4}$.

Santos $(1987)^{5}$, no Brasil, um pioneiro na investigação das novas tecnologias da ótica das ciências sociais, analisa a submissão da produção ao desenvolvimento científico e tecnológico e os impactos desse desenvolvimento sobre o crescimento econômico. A tese de Santos, na época, era que:

(...) a evolução da tecnologia dentro do modo de produção capitalista leva à separação crescente entre o trabalhador e os meios de produção. Estes [os meios de produção, pensando como máquinas, equipamentos e, por certo, sem a inclusão das instalações e da terra] se autonomizam e passam a ser dirigidos pelo computador (Santos, 1987, p.11, grifos meus).

Portanto, para Santos, as máquinas dirigem a produção. Nesse sentido, seriam capazes de pensar e, portanto, seriam inteligentes porque pensam. Ora, como se disse antes, não há, até o ano 2000, uma única máquina inteligente. Mesmo o Deep Blue, um super computador que ganhou uma partida de xadrez do Kasparov, foi considerado uma máquina inteligente no sentido de que seria capaz de criar alguma coisa. Por trás daquele computador estavam quatro engenheiros de computação. Na verdade, o enxadrista jogou contra uma máquina e quatro homens.

Mas nada disso é muito importante. O mais premente é que, mesmo não tendo explicitado um conceito de tecnologia, pode-se supor que, para Santos (1987), tecnologia ainda seria o "saber operacional" das máquinas e equipamentos. E mais, como Marx, ele imagina que o sistema de máquina se autonomiza, torna-se livre para dirigir a produção.

${ }^{4}$ Keth Pavitt retoma a discussão sobre transferência de tecnologia, feita antes por ela mesma num artigo de 1991 intitulado How economically userfull is basic research. Christian Walter é um analista financeiro que discute o emprego da econometria e das análises das séries matemáticas sobre as decisões tomadas pelas empresas, sem interessar-se muito pelo tema da obra para a qual está escrevendo.

5 "A revolução científica e tecnológica e a acumulação do capital" é a tese de doutoramento de Santos, cuja publicação, no Brasil, demorou muito. Os dados empíricos referem-se aos anos de 1964 a 1972; portanto, bem antes dos computadores pessoais (PC) da IBM de arquitetura aberta, que são de 1981. 
Revista Eletrônica de Ciência Administrativa (RECADM) - ISSN 1677-7387

Faculdade Cenecista de Campo Largo - Coordenação do Curso de Administração v. 2, n. 2, nov./2003 - http://revistas.facecla.com.br/index.php/recadm/

Se for assim, pode-se dizer que a ciência é uma força de trabalho, um sujeito, e não o cientista, como imagino. Veja o que fala Santos:

A ciência substitui o conhecimento empírico - essa é uma tarefa da ciência, desde Aristóteles, substituir a 'empeiria' na produção, e esta se torna progressivamente um ramo da atividade científica (Ibid., p.11).

Se Santos tivesse falando de gestão da força de trabalho, e não de máquinas presumidas inteligentes, ou do Maravilhoso Mundo Novo de Huxley, eu não teria de que discordar. Veja-se como segue a fala.

Em conseqüência, a empresa capitalista procura integrar a produção do
conhecimento científico no seu interior e convertê-la numa fração do capital. Os
resultados da atividade do conhecimento são progressivamente monopolizados e
se transformam em instrumento de luta interempresarial. A pesquisa fundamental
e aplicada, e principalmente o desenvolvimento final dos produtos [P\&D] passam a
configurar um momento essencial do ciclo do capital; a atividade do Estado se
torna então necessária para assegurar este vasto processo de acumulação e
aplicação do conhecimento científico (Ibid., p.11-12).

Entretanto, há uma crença geral de que o emprego crescente de novos materiais, máquinas, equipamentos, enfim, as mudanças nas organizações, sistemas e métodos levariam as empresas à busca de trabalhadores cada vez mais qualificados, tendo em vista as exigências da própria complexidade das organizações.

Resumindo, muitos pesquisadores falam de novas tecnologias industriais, mas os conceitos de tecnologias e de técnicas permanecem presumidos. Para todos os textos que foram examinados aqui, parece que tecnologia refere-se apenas ao saber incorporado por máquinas e equipamentos ou, quando muito, referem-se à engenharia. Nenhum deles admitiu que a OSM é uma tecnologia estruturada sob o mesmo princípio instrumental do sistema de máquinas. E mesmo os que tratam da importância da OSM, falam como se ela fosse outra coisa que não tecnologia. Apenas Veltz aventura-se pelo conceito de tecnologia, mas ainda preso à idéia de que tecnologia é, no limite, um sistema de inteligência artificial, ou seja, não se liberta da máquina nem da instrumentalidade da razão técnica.

O principal mérito, do ponto de vista do trabalhador, de muitas dessas pesquisas sobre tecnologias duras (máquinas e equipamentos) é haver notado que a grande mudança na indústria era OSM, ou seja, era a cultura e a conduta organzacional.

Quanto aos impactos das novas tecnologias (duras, claro) sobre o cotidiano do trabalho e da indústria, deduz-se que, na visão de muitos pesquisadores, a técnica (nesse caso uma coisa) é, por si, emancipatória. Há a esperança clara num futuro melhor exatamente porque a revolução das novas tecnologias trariam consigo uma vida melhor uma idéia que lembra a idéia de dominação libertadora (ver Habermas, 1987, p.51 e Marcuse, 1978, p. 19).

Parece haver uma ausência dos sujeitos coletivos (Estado, Nação, classes, grupos) nesse discurso tecnicista e, portanto, ausência de conflitos de interesse de pessoas e grupos, antagonismos que Durkheime encontrou entre as tribos fraternas dos cacatuas brancos e pretos, na Austrália, e Marx, entre trabalhadores assalariados e capitalista.

O capital, a política e as tradições culturais (mundo vivido) não estão nessa narrativa sobre o desenvolvimento tecnológico. Parece que os processos de trabalho e os saberes são neutros e que o capital e a política não fazem uso das novas tecnologias (máquinas, materiais, equipamentos, processo, sistemas etc.) segundo seus próprios interesses e valores. 
Revista Eletrônica de Ciência Administrativa (RECADM) - ISSN 1677-7387

Faculdade Cenecista de Campo Largo - Coordenação do Curso de Administração

v. 2, n. 2, nov./2003 - http://revistas.facecla.com.br/index.php/recadm/

Quanto à relação da intensidade do trabalho e automação, em Coriat (1988) o emprego das tecnologias mais flexíveis, principalmente as máquinas com processadores programáveis, e a fixação dos custos de produção (ou preços de custo em Marx) passa a se basear cada vez menos na intensificação do trabalho vivo e cada vez mais na taxa de utilização das máquinas e instalações. Passa-se, no entendimento de Corriat, de um paradigma de preços ancorado na organização do trabalho (o taylorismo e o fordismo) para um paradigma baseado na organização da produção. Essa transição aponta para um esforço de enfatizar uma gestão mais otimizada do capital fixo e do capital circulante, com a conseqüente inflexão das pressões relativas à intensificação do trabalho. Coriat retorna ao velho vício advindo da Primeira Revolução Industrial: a tecnologia é uma razão autárquica e emancipatória, como em Grundrisse (Marx e Engels, 1985).

Outro descuido de Coriat (1988) foi não ter percebido a diferença entre a idéia de lucro entre empresários, fixado numa operação de subtração de receitas menos despesas, o conceito de lucro da Economia Política e da Teoria da Regulação radicado nas teorias da mais-valia. Para as empresas, só há lucro se há saldo de caixa. Para preços de produção pré-fixados, quanto menor a despesa, maior o lucro. O empresário só tem algum controle sobre as despesas. As receitas são expectativas e não fatos.

Se fosse assim, se as empresas não estivessem tão interessadas no controle dos custos, por que reduziriam a intensidade do trabalho, se essa conduta significa perda de eficácia e aumento dos custos dos salários? Por que imobilizariam mais capital, na figura de máquinas e equipamentos, se pode evitar ou desimobilizar (terceirizar)? Coriat (1988) nem trata dessas questões; entretanto, reduzir custos e evitar imobilizar capital são referências paradigmáticas da produção enxuta (Womack; Roos; Jones, 1992).

Não considerando nada disso, Coriat (1988), impressionado com as possibilidades das máquinas com controle programável de 1980, não despertou para o papel que a organização passaria a desempenhar no novo modelo de gestão. O que as pesquisas mais recentes indicam e que o "ohnismo" apregoa é a intensificação e simplificação do trabalho, ou seja, uma combinação do taylorismo com o toyotismo.

Em face das novas tecnologias, os pesquisadores se deixam seduzir pelas possibilidades de emprego das novas técnicas, máquinas e equipamentos, esquecendose que a forma, a totalidade das determinações de uma mercadoria está sujeita às vicissitudes e à lógica mercantil da sociedade capitalista. As máquinas, numa empresa, não existem para poupar trabalho, mas para gerar receita ${ }^{6}$. Sendo assim, pouco fica, dessa discussão toda, além dos dados sobre o atraso tecnológico brasileiro e a observação de que sendo uma economia tecnologicamente atrasada, o desemprego industrial no Brasil dificilmente seria explicado pelo uso intensivo de capital-máquina.

A sedução, o encantamento dos pesquisadores com as novas tecnologias têm uma racionalidade própria. Ela diz respeito à concepção moderna de ciência, formulada sem rodeios por Bacon. Este, no Novum Organum, diz com todas as letras: "Ciência e poder do homem coincidem (...) Pois a natureza não se vence quando não se the obedece" (Aforismo III). Sendo um poder, submetendo a natureza, as novas tecnologias são uma maravilha da razão instrumental. Se há danos, estes são os ônus inevitáveis do processo civilizatório. Será...?

A razão comunicativa - aquela que se orienta por normas compartilhadas e aceitas pelos indivíduos que interagem, baseados em uma comunicação que visa uma compreensão comum da vida - não tem o mesmo poder por se opor à hegemonia de uma razão do tipo instrumental. E, assim, criticar o entusiasmo com técnicas presumindo que

${ }^{6}$ Os Bancos 24 Horas, por exemplo, debitam na conta do usuário o preço das comodidades que oferecem. As comodidades são o valor de uso das mercadorias que constituem os serviços bancários. 
Revista Eletrônica de Ciência Administrativa (RECADM) - ISSN 1677-7387

Faculdade Cenecista de Campo Largo - Coordenação do Curso de Administração v. 2, n. 2, nov./2003 - http://revistas.facecla.com.br/index.php/recadm/

elas não existem fora dos interesses dos sujeitos coletivos no poder, fora do Estado ou livres de qualquer interesse hegemônico soa como obscurantismo. Na verdade, essa é a posição da crítica werberiana à razão instrumental.

Para Weber, "racionalização significa, em primeiro lugar, a ampliação das esferas sociais, que ficam submetidas aos critérios da decisão racional" (Habermas, 1987, p.45). Racionalidade é “... uma 'coerência' lógica ou teleológica” (Weber, 1980, p. 371). Ou seja:

A racionalidade tecnológica protege assim antes a legalidade da dominação em vez de a eliminar e o horizonte instrumentalista da razão abre-se a uma sociedade totalitária de base racional (Habermas, 1987, p. 49).

A crítica ao discurso racional instrumental dos pesquisadores seduzidos pelas novas técnicas apenas presume que há outras esferas de racionalidade além da razão cartesiana. Nesse sentido, para a perspectiva do que vive do trabalho, a emancipação e a eticidade não podem ser submetidas às determinações da razão instrumental.

\section{BIBLIOGRAFIA CONSULTADA}

A EXPERIÊNCIA Brasileira: o caso de São Paulo. In: SEMINÁRIO INTERNACIONAL DE PARQUES TECNOLÓGICOS, 107., 1987. Rio de Janeiro. Anais... Disponível em: $<h t t p: / / w w w . v e n t u r e c a p i t a l . c o m . b r / g l o s s a r i o . h t m>$. Acesso em 10/08/2000.

ANPROTEC. Incubadora de Empresas. Disponível em $<$ http://www.anprotec.org.br/anprotec.html >. Acesso em 18/08/2000.

ANPROTEC. Parques Tecnológicos. Disponível na Internet $<$ http://www.anprotec.org.br/anprotec.html >. Acesso em 18/08/2000. ASSOCIAÇÃO NACIONAL DE P, D\&E DAS EMPRESAS INOVADORAS - ANPEI. Indicadores empresariais de inovação tecnológica. In: Instrumento de Coleta de Dados. São Paulo: FINEP, 1999. Projeto Inovar. Glossário. Disponível em: <http://www.venturecapital.com.br/glossario.htm> Acesso em 10/07/2000.

BARBOSA, Antônio Luiz Figueira. Sobre a propriedade do trabalho intelectual: uma perspectiva crítica. Rio de Janeiro: UFRJ, 1999.

BAXTER, Mike. Projeto de Produto: guia prático para o desenvolvimento de novos produtos. Trad. Itiro lida. São Paulo: Editora Edgard Blucher, 1998. In: FINEP. Projeto Inovar: Glossário. Disponível em: <http://www.venturecapital.com.br/glossario.htm>. Acesso em 10 jul. 2000

BID. Oficina de Evaluación (EVO). Evaluación: una herramienta de gestión para mejorar el desempeño de gestión para mejorar el desempeño de los proyetos. Washington: BID, 1997. In: FINEP. Projeto Inovar. Glossário. Disponível em: $<$ http://www.venturecapital.com.br/glossario.htm>. Acesso em 10/07/2000.

BOLLINGER, Lynn et al. A Review of literature and hypothesis on new technology - based firms. In: Research Policy, 12, p. 1-14, 1983. FINEP (Projeto Inovar. Glossário). Disponível em: <http://www.venturecapital.com.br/glossario.htm>. Acesso em 10/07/2000.

BUSS, Paulo Marchiori; RAMOS, Célia Leitão. Desenvolvimento Local e Agenda 21: Desafio da Cidadania. Rio de Janeiro, Centro de Tecnologia, Trabalho e Cidadania Oficina Social, Cadernos da Oficina Social N. ${ }^{\circ} 3$, fev./2000.

CANTER, L. Environmental impact assessment. Oklahoma: McGraw Hill , 1977. In: FINEP. Projeto Inovar. Glossário. Disponível em: $<$ http://www.venturecapital.com.br/glossario.htm>. Acesso em 10/07/2000.

CASSIOLATO, J. E.; LASTRES, H. M. Parcerias Estratégicas, nº8, maio/2000, MCT. In: FINEP. Projeto Inovar. Glossário. Disponível em: http://www.venturecapital.com.br/glossario.htm>. Acesso em 10/07/2000. COMITÉ DE ENTIDADES PÚBLICAS NO COMBATE À FOME E PELA VIDA - COEP. Carta de Princípios Orientadores para a Implementação do Programa de Desenvolvimento Integrado e Sustentável de Manguinhos. Rio de Janeiro, 1999. 
Revista Eletrônica de Ciência Administrativa (RECADM) - ISSN 1677-7387

Faculdade Cenecista de Campo Largo - Coordenação do Curso de Administração v. 2, n. 2, nov./2003 - http://revistas.facecla.com.br/index.php/recadm/

DI BLASI, Clésio Gabriel. A propriedade Industrial. Rio de Janeiro, Guanabara Dois, 1982. GUIMARÃES, Fábio Celso de Macedo Soares. A Política de incentivo à inovação. In: FINEP. Projeto Inovar. Glossário. Disponível em: http://www.venturecapital.com.br/glossario.htm>. Acesso em 10/07/2000.

FINEP - FINANCIADORA DE ESTUDOS E PROJETOS. Apoio à gestão da qualidade AGQ. In: NEP-COMP/01.00/1998. Rio de Janeiro: FINEP, 1998.

Apoio ao plano de negócios de parceiros tecnológicos. In: NEPPART/01.00/1998. Rio de Janeiro: FINEP, 1998.

Apoio ao desenvolvimento tecnológico da empresa nacional - ADTEN. In: NEPCOMP/02.00/1998. Rio de Janeiro: FINEP, 1998.

. Departamento de Estudos e Estratégias Sociais. Rio de Janeiro, 2

Elaboração, aprovação e avaliação de planos de negócios. In: NPDEN/02.00/1998. Rio de Janeiro: FINEP, 1998.

Estabelecimento de Programas e Ações Estratégicas. In: NORMA NDEM/03.00/1999. Rio de Janeiro: FINEP, 1999.

Projeto Inovar: Glossário. Disponível em: <http://www.venturecapital.com.br/glossario.htm>. Acesso em 10/07/2000.

Sistema de Indexadores para a FINEP. Rio de Janeiro, 1994.

Superintendência de Estudos e Estratégias Setoriais . Categorização das Empresas Clientes Finep. Rio de janeiro, 2000.

FREEMAN, C. ; PEREZ,C. Technical Change and Economic Theory. London, 1988.

FUNDAÇÃO CHRISTIANO OTTONI. Glossário da Qualidade Total. Elaborado por Alberto Amarante Macedo e Francisco I. Póvoa Filho. Belo Horizonte: Fundação Christiano Ottoni, 1995.

FUNDAÇÃO ESTADUAL DE ENGENHARIA DO MEIO AMBIENTE. Vocabulário Básico do Meio Ambiente. Compilado por lara Verocai Dias Moreira. Rio de Janeiro: Serviço de Comunicação Social da Petrobrás, 1990. In: FINEP. Projeto Inovar. Glossário. Disponível em: <http://www.venturecapital.com.br/glossario.htm>. Acesso em 10/07/2000.

GUEDES PEREIRA, Maurício et al. A Experiência Brasileira. In: SEMINÁRIO INTERNACIONAL DE PARQUES TECNOLÓGICOS. Anais ..., p. 108-157. Rio de Janeiro: FINEP, dez. 1987. Disponível em: <http://www.venturecapital.com.br/glossario.htm>. Acesso em 10/07/2000.

GUEDES PEREIRA, Maurício. Um Estudo sobre Empresas Geradas a partir de Universidades no Brasil. In: SIMPÓSIO NACIONAL DE PESQUISA, 15., anais ... PACTo/FEA/USP, p. J.04, out. 1990. Disponível em: $<$ http://www.venturecapital.com.br/glossario.htm>. Acesso em 10/07/2000.

GUIMARÃES, Fábio Celso de Macedo Soares. A interação entre pesquisa \& desenvolvimento e produção industrial no Brasil. Rio de Janeiro: MCT, 1992.

GUIMARÃES, Fábio Celso de Macedo Soares. A Política de Incentivo à Inovação. Rio de Janeiro: FINEP, 2000.

HORBERRY, J. Status and application of EIA for development. Gland, Conservation for Development Centre, 1984. In: FINEP. Projeto Inovar. Glossário. Disponível em: <http://www.venturecapital.com.br/glossario.htm>. Acesso em: 10/07/2000.

HUXLEY, Aldous Leonard. Admirável mundo novo. São Paulo: Abril Cultural, 1982.

HURTUBIA, J. Ecologia y desarrollo: evolución y perspectivas del pensamento ecológico. In: Estilos de desarrollo y medio ambiente. México: Fondo de Cultura Económica,1980. Disponível em: http://www.venturecapital.com.br/glossario.htm>. Acesso em 10/07/2000.

IBICT. Rede Nacional de Trasferência e Difusão de Tecnologias Apropriadas. Disponível em: <http:// www.ibict.br>. Acesso em 17/08/2000.

IBICT. Rede Nacional de Trasferência e Difusão de Tecnologias Apropriadas. Disponível em: <http://INPI>. Acesso em 10/07/2000. 
Revista Eletrônica de Ciência Administrativa (RECADM) - ISSN 1677-7387

Faculdade Cenecista de Campo Largo - Coordenação do Curso de Administração v. 2, n. 2, nov./2003 - http://revistas.facecla.com.br/index.php/recadm/

INPI - INSTITUTO NACIONAL DA PROPRIEDADE INDUSTRIAL. Patente e Desenho Industrial. Disponível em: <http://www.inpi.gov.br>. Acesso em 10/07/2000.

INTERIN MEKONG COMITEE. Environmental impact assessment guidelines of application to tropical niver basin development. Bangkok: Mekong Secretariat, 1982. In: FINEP. Projeto Inovar. Glossário. Disponível em: $<$ http://www.venturecapital.com.br/glossario.htm>. Acesso em 10/07/2000.

ISO 9000 . (NB - 9001) - Sistemas de qualidade - Modelo para garantia da qualidade em projeto / desenvolvimento, produção, instalação e assistência técnica.

ISO 9000 . (NB - 9002) - Sistemas de qualidade - Modelo para garantia da qualidade em produção e instalação.

ISO 9000 . (NB - 9003) - Sistemas de qualidade - Modelo para garantia da qualidade em inspeção e ensaios finais.

ISO 9000 . (NB - 9004) - Gestão da qualidade e elementos do sistema qualidade Diretrizes.

ISO 9000 . Designação do conjunto de cinco normas internacionais sobre Gerencia da Qualidade e Garantia da Qualidade. Normas de gestão da qualidade e garantia da qualidade - Diretrizes para seleção e uso. (NB 9000).

JURAN, J.M. ; GRYNA, Frank M. Controle da qualidade, conceitos, políticas e filosofia da qualidade. São Paulo: McGraw-Hill, 1991.

LA ROVERE, Emílio Lèbre (Coord). Manual de auditoria ambiental. Rio de Janeiro: Qualitymark, 2000.

LASTRES, Helena et al.. Globalização e Inovação Localizada: experiências de Sistemas locais no âmbito do Mercosul e proposições de políticas de C\&T. Nota Técnica 01/99. Rio de Janeiro: IE/UFRJ, 1998.

LEMOS C. Inovação na era do conhecimento. Parcerias Estratégicas, n 8. MCT, 2000.

LONGO, W.P. Conceitos Básicos sobre Ciência e Tecnologia. Rio de Janeiro: FINEP, 1996. v.1.

LONGO, W.P. Conceitos Básicos sobre Ciência e Tecnologia. Rio de Janeiro, FINEP, 1996. v.1.

MAIMON, Dália. Passaporte Verde: Gerência Ambiental e Competitividade. Rio de Janeiro: Qualitymark, 1996.

MARTÍNEZ, Eduardo; ALBORNOZ, Mario. Indicadores de ciencia y tecnología: Estado del arte y perspectivas. Caracas: UNESCO, 1998. Disponível em: <http://www.venturecapital.com.br/glossario.htm>. Acesso em 10/07/2000.

MCKINSEY \& COMPANY. Desenvolvimento dos programas de ação para o "cluster" de biotecnologia em Belo Horizonte: Projeto Cresce Minas. Belo Horizonte, FIEMG/CIEMG/SESI/SENAI/IEL 1999.

MINISTÉRIO DA CIÊNCIA E TECNOLÓGIA. Conceitos (Glossário). 1997. In:FINEP. Projeto Inovar. Glossário. Disponivel em: <http://www.venturecapital.com.br/glossario.htm>. Acesso em 10/jul./2000.

NBR ISO8402 - Gestão da qualidade e garantia da qualidade - Terminologia. Rio de Janeiro, ABNT, jul.1993.

OECD. Frascati Manual. Paris, OCDE, 1993.

OECD. Oslo Manual. Paris, OCDE/Eurostat, 1997.

PERILO, Sérgio; NASCIMENTO, Paulo. A Tecnologia como condicionamento do perfil de um polo tecnológico. In: SIMPÓSIO NACIONAL DE PESQUISA, 16., Anais ... Vol. II, PACTo/FEA/USP, p. G-23 - G-39, Rio de Janeiro, out. 1991. Disponível em: $<$ http://www.venturecapital.com.br/glossario.htm>. Acesso em 10/07/2000.

SANTOS, Silvio A. dos. Criação de Empresas de Alta Tecnologia. São Paulo: Pioneira, 1987. Disponível em: <http://www.venturecapital.com.br/glossario.htm>. Acesso em 10/07/2000. 
Revista Eletrônica de Ciência Administrativa (RECADM) - ISSN 1677-7387

Faculdade Cenecista de Campo Largo - Coordenação do Curso de Administração v. 2, n. 2, nov./2003 - http://revistas.facecla.com.br/index.php/recadm/

SECRETARIA EXECUTIVA DA COMUNIDADE SOLIDÁRIA. Documento de Referência do Programa Comunidade Ativa: Uma Estratégia de Indução ao Desenvolvimento Local Integrado e Sustentável. Brasília, 1999.

SELDEN, M. et al.. Studies on environment. Washington: Environmental Protection Agency,1973. Disponível em: <http://www.venturecapital.com.br/glossario.htm>. Acesso em 10/07/2000.

VENTURE CAPITAL. Disponível em: <http://www.venturecapital.com.br/glossario.htm> WERKEMA, Maria Cristina Catarino. As ferramentas da qualidade no gerenciamento de processos. Belo Horizonte: UFMG/EE/Fundação Christiano Ottoni, 1995. 